\title{
THE RELIABLE APPLICATION OF AVERAGE AND HIGHLY VISCOUS MEDIA
}

Assembly Net

Thomas A. Lenz and Nabih M. Othman

Fraunhofer IPA, Department of Cleanroom Manufacturing, Nobelstrasse 12, 70569 Stuttgart, Germany

Abstract: The use of bonding as a joining technique is gaining more and more importance in micro manufacturing. There is a demand for systems which are capable of reliably dispensing tiny amounts of adhesive, especially under industrial conditions. By integrating sensors into the dispensing system or checking process results there is the possibility to become aware of the system specific problems and options of improvement. Methods and systems of investigation have been developed and realized at the Fraunhofer IPA.

Key words: Process control, process monitoring, sensor integration, dispensing, adhesive bonding, micro assemble, vision system.

\section{INTRODUCTION}

New demands are being placed on manufacturing engineering as a result of increasingly miniaturized components, frequent product changes and alterations in the batch sizes of life style products such as mobile phones, PDAs, cameras, etc. For the manufacturer, this means having to adapt production systems to new circumstances and ensuring adequate process stability for the required piece numbers within a very short space of time (Hennemann, 1992).

Bonding techniques are becoming more and more popular as a joining technology for fixing and contacting components (Luchs, 1998). Ideally, it 
should be possible to adjust dispensing systems simply and accurately to produce and maintain a high volume constancy and reproducibility of adhesive application (Gaugel, 2003).

Although current dispensing systems are capable of reliably creating tiny structures both of unfilled adhesive or filled conductive adhesive under laboratory conditions, in industry changes in operating conditions such as fluctuations in material temperature due to warming, variations in batches and many other factors lead to deviations in feeding volumes and thus to the application of faulty structures. Figure 1 shows the results of such changes when the feeding volume at the tip of the needle varies in an uncontrolled manner or is not noticed (Othman, 2004).
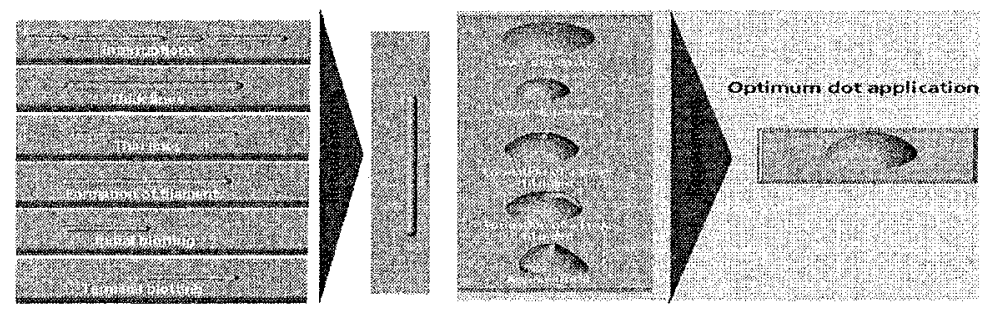

Figure 1. Faults in the application of adhesive due to fluctuations in flow rates.

Most of the dispensing systems currently available on the market still require optimization as they do not possess sensors which can measure fluctuations in parameters relevant to the manufacturing process and thus react accordingly. Therefore, with a view to increased productivity, flexibility and reliability, controlled systems for the accurate application of dots and lines of highly-viscous adhesives (especially conductive adhesives) are required. Methods for investigating dispensing systems, targeted parameter studies and mathematical models are needed to pave the way for more efficient dispensing systems.

\section{FACTORS INFLUENCING THE DISPENSING PROCESS}

Experiments carried out at the Fraunhofer institute concerned with application of conductive adhesives have shown that the dispensing process is not only dependent upon the correct selection of the application method or 
system but much more upon the correct process parameters for the application in question. As well as the dispensing system itself with its reservoir (e.g. cartouche), the dispensing needle, adhesive, substrate and handling system also need to be taken into consideration (Figure 2.).

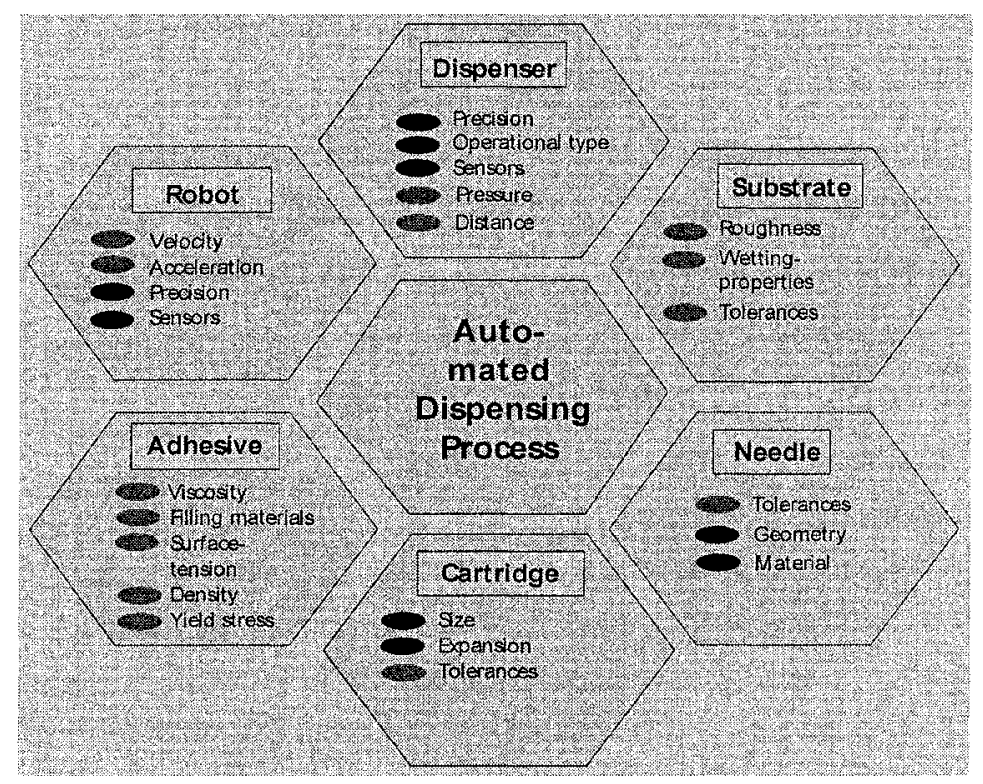

Figure 2. Parameters influencing the dispensing result:

Parameter Group A (not alterable),

Parameter Group B (alterable before commencement of dispensing process),

Parameter Group C (atterable even during dispensing process)

Parameters influencing the dispensing result can be divided into three groups:

- The influencing factors listed in Parameter Group $\mathbf{A}$ are parameters which cannot be altered or influenced by the user. The viscosity, dropping time and conductivity of an adhesive are all examples of such parameters.

- The factors listed in Parameter Group B include parameters which can be altered before the actual dispensing process but not during it. An example of this is expansion of the cartouche which can be minimized if the user takes appropriate measures beforehand. 
- Parameter Group C includes parameters which can be altered during the dispensing process. One example here is the traveling velocity of the robot.

When defining the requirements of a reliable overall system, especially the technological parameters listed in groups $\mathrm{B}$ and $\mathrm{C}$ need to be taken into account. Many of these parameters have been investigated at the Fraunhofer IPA (Othman, 2004).

\section{INVESTIGATION METHODS}

Once possible deficits and influencing factors have been defined, current analysis methods and a general procedure need to be determined.

\subsection{Monitoring the process}

In order to achieve targeted process monitoring, sensors which have been adapted to meet the measurement task requirements in question have to be integrated. As the main issue here is not the development of special sensors, miniaturized sensors currently available on the market have been used which have either been integrated into sensor adapters for universal implementation or, where possible, integrated directly into the systems themselves.

In the field of miniaturized sensors, the choice of available sensor systems is relatively narrow, the price usually extremely high and delivery times invariably considerably lengthy. These circumstances mean that compromises have to be made regarding the construction of the individual systems in order to achieve a high degree of flexibility and universal implementation. Figure 3 shows the first prototype utilized. A special optical monitoring device for microfluidic systems is presented in another paper (Güttler, S.; Lenz, Th. A., 2005). 


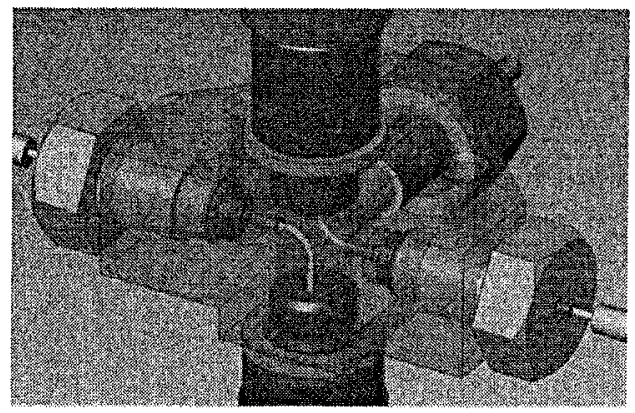

Figure 3. CAD model of the first prototype of a sensor adapter with integrated pressure and temperature sensors.

After further experiments concerned with construction and joining technologies, sealing techniques and the integrated sensor technology of this adapter, it was possible to create optimized systems for special applications as shown in Figure 4.
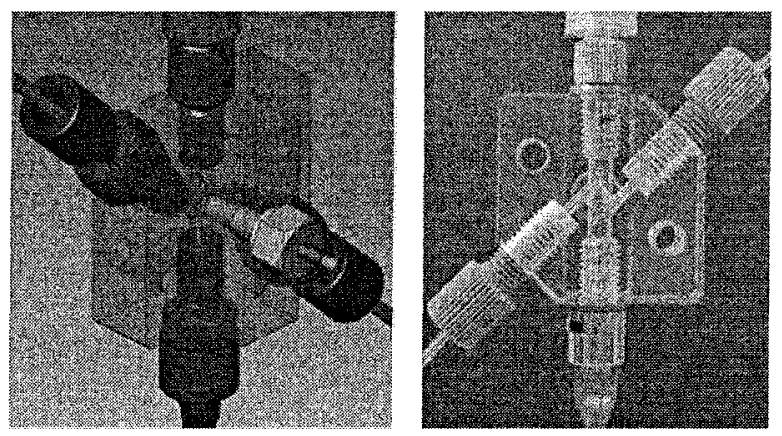

Figure 4. Sensor adapter optimized with regard to flow rates and dead volumes.

Through the use of standard fittings, the adapter can be rapidly integrated into a number of dispensing systems. The use of detachable sealed sensor elements enables these integrated sensors to be reused, thus avoiding unnecessary costs.

The benefit of using transparent material lies in the ability to monitor hidden and inaccessible spaces. However, before this monitoring tool can actually be implemented, further geometrical optimizations need to be carried out on the system and additional developments made to the sealing concept. 


\subsection{Checking process results}

In order to be able to correctly assess the process results, both the dots and lines dispensed by the system need to be accurately measured and investigated. Gravimetric methods are only partially suitable as the mass decreases by the cube of the geometric dimensions. Thus, a drop of adhesive $1 \mathrm{~mm}^{3}$ in size weighs approx. $1 \mathrm{mg}$ and a drop $100 \cdot 100 \cdot 20 \mu \mathrm{m}^{3}$ in size only $0.2 \mu \mathrm{g}$.

For reliable assessments regarding dispensing results in micro and nano assembly, primarily only optical methods are suitable as these are capable of measuring structures just a few micrometers in size. A high-performance vision system for in-line process control has been implemented at the institute using an SCC system (primarily developed for measuring particles on technical surfaces).

The system is capable of recording and measuring dot diameters smaller than $500 \mu \mathrm{m}$ and line widths less than $500 \mu \mathrm{m}$. Any deviations from a desired pre-given geometry are recognized and reported. The measuring principle of an SCC camera is based on combined, flat, lateral illumination and / or incidental light from the test surface (Figure 5). In this way, an acceptable level of contrast can be achieved between the dots/lines dispensed and the rough surface they are on. With the aid of image-processing methods, they can be used to automatically record dots or lines. The system is able to reliably record and analyze dot diameters or line widths measuring approx. $8 \mu \mathrm{m}$ (Grimme, R.; Klumpp, B., 1998).
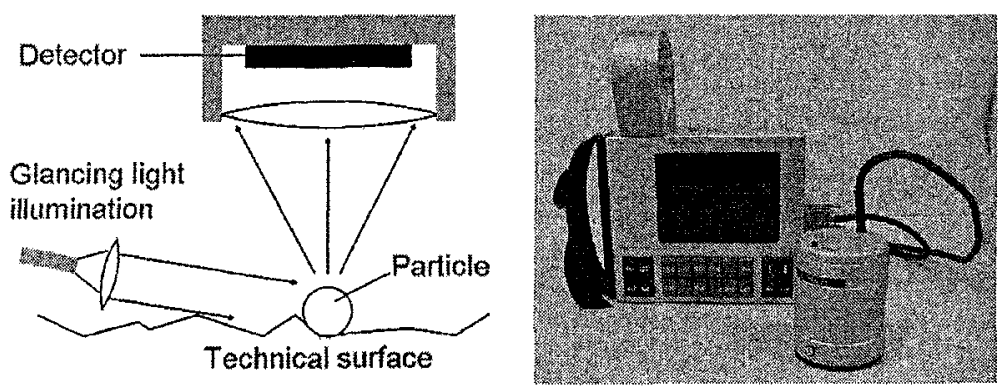

Figure 5. Prototype of a hand-held device for recognizing dots or lines on surfaces. Left: diagram of the principle of glancing light excitation inside a probe / Grimme 1998; Right: hand-held device with probe 


\section{PRESENTATION OF THE RESULTS}

\subsection{Measurement procedures / methods for monitoring process parameters}

An overview of the results obtained is given below. To demonstrate investigations on system behavior, an under-supplied pump unit was used which was unable to prime enough medium because its lines were too narrow; as a result, cavitation effects occurred causing a strong, highfrequency pulsation of pressure values, as shown in Figure 6. A possible optimization solution would be to redesign the system by enlarging the cross-section of the lines, thus increasing process reliability.

With this and many other problems, it may be helpful to take the overall system or the process step and its environment into consideration in the investigations in order to find a solution.

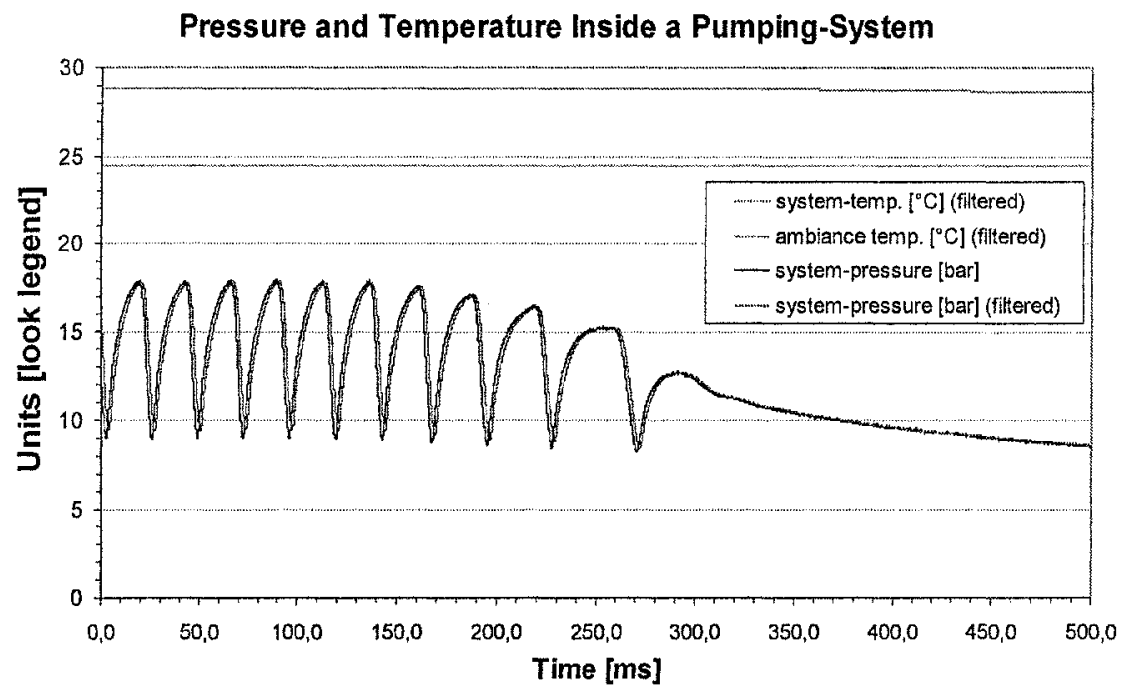

Figure 6. Pulsation inside a pumping unit due to cavitation effects. 


\subsection{Measurement procedures for controlling process results}

The performance of the systems mentioned here was verified on dots and lines applied to silicone and ceramic substrates. In order to obtain statistical certainty, 10,000 dots or 100 lines were applied respectively and investigated using the various measuring methods.
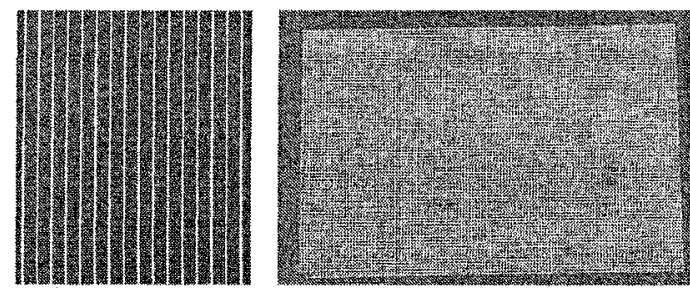

Figure 7. Results with a commercial or industrial vision system

Conventional vision systems used in industrial applications such as those shown in Figure 7 are suitable for controlling placement and components. However, when used in the field of microsystem technology, these systems have their limitations as far as their degree of resolution and 3-dimensional geometry recognition are concerned.

A device developed at the Fraunhofer IPA and marketed by acp (advanced clean production) does not have these disadvantages. Tests made to date have shown that dots and lines which have been applied can be accurately measured. Figure 8 . shows improvements in contour and geometry recognition which have been achieved using the methods of illumination possible with an SCC camera unit. This method is suitable for in-line integration; testing times are comparable with those of conventional vision systems due to the fact that most of the optimizations have been carried out at camera level. 

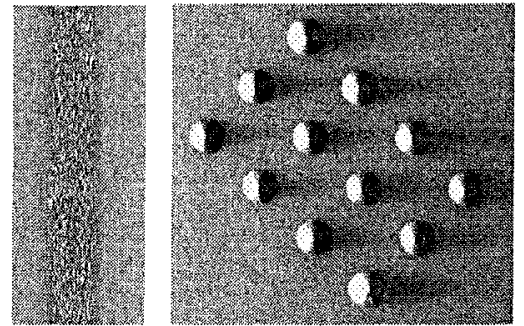

Figtre 8. Results obtained with an SCC camera using only incidental light (left) and using glancing light combined with incidental light (right).

A laser scanning microscope (LSM) is used as a reference method / measuring system. Using the principle of light sections, this device is capable of depicting volume models of convex three-dimensional objects and of measuring them with an accuracy of approx. $1 \mu \mathrm{m}$. However, due to the long measuring times involved and the very small field of vision $\left(200 \times 200 \mu \mathrm{m}^{2}\right)$, this method is only suitable as a control or reference system. Figure 9 shows the measurement of volumes and of dot diameters and line widths of each of the dots/lines applied.
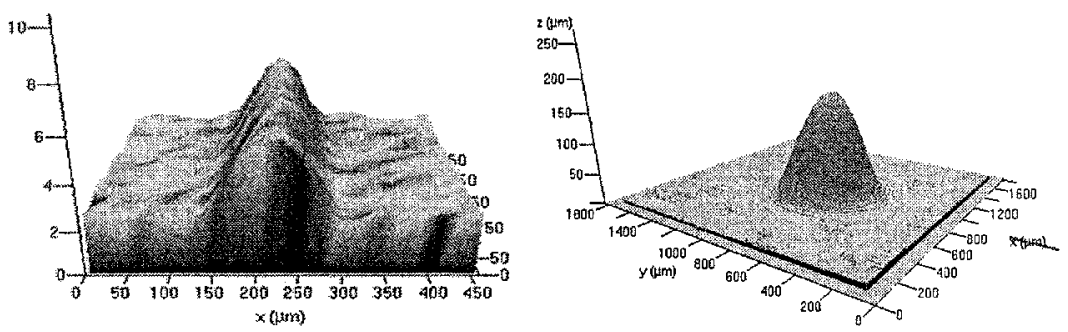

Figure 9. Test results obtained using an LSM.

\section{REFERENCES}

1. Gaugel, Tobias, 2003, Verfahren zum flexiblen Mikrodosieren von isotrop leitfähigen Klebstoffen, University of Stuttgart.

2. Grimme, R., Klumpp, B., 1998, Vorrichtung und Verfahren zur Überprüfung einer Oberfläche eines Gegenstandes, (10-1998), Patent: DE 19716264 A1. 
3. Güttler, Stefan; Lenz, Thomas A., 2005, Mikrodurchflusssensorik für höherviskose Fluide, Springer, WT-Online (03-2005), pp. 162 et sqq.

4. Othman, Nabih 2004, Präzise Mikrodosierung von nieder-, mittel- und hochviskosen Medien, Adhäsion 48 (6-2004), pp. 22 et seqq.

5. Möller, Markus, 2002, Mikroapplikation von ungefüllten Klebstoffen zum Kleben in der Mikrosystemtechnik, Shaker Verlag, 2002, Aachen; also University of Aachen.

6. Hennemann, O. D., 1992, Handbuch Fertigungstechnologie Kleben, Carl Hanser Verlag, 1992, Bremen.

7. Luchs, R., 1998, Einsatzmöglichkeiten leitender Klebstoffe zur zuverlässigen Kontaktierung elektronischer Bauelemente in der SMT, Meisenbach Verlag, 1998, Bamberg; also University of Erlangen. 